\title{
"Entre vidas e mortes, entre máscaras e fugas": um estudo sobre a prática médica hospitalar
}

| 1 Janaína Souza Aredes, ${ }^{2}$ Ana Lúcia Modesto |

Resumo: Nas sociedades complexas, confere-se aos médicos um saber sobre-humano que desafia a morte e a contesta como parte da vida. Nos serviços de urgência e emergência, diversos profissionais atuam diuturnamente e de modo muito próximo com a vida e com a morte. Este artigo analisa a prática médica ocidental a partir de um trabalho etnográfico realizado junto a médicos que trabalham num serviço de urgência e emergência de uma grande cidade.

Buscou-se compreender a forma como esses médicos, enquanto indivíduos, sujeitos e profissionais lidam com a vida e com a morte em sua práxis. A análise dos dados apontou para relaçôes éticas, institucionais, culturais e idiossincráticas na atuação médica diante $\mathrm{da}(\mathrm{s}) \operatorname{vida}(\mathrm{s})$ e da(s) morte(s) das pessoas assistidas.

> Palavras-chave: Biomedicina; discurso; prática médica.

\footnotetext{
1 Centro de Pesquisas René Rachou/Fiocruz, Laboratório de Epidemiologia e Antropologia Médica. Belo Horizonte-MG, Brasil (janainaaredes@gmail. com).

${ }^{2}$ Universidade Federal de Minas Gerais, Departamento de Sociologia. Belo Horizonte-MG Brasil (modesto926@terra. com.br).
}

Recebido em: 28/05/2015 Aprovado em: 10/08/2015 


\section{Introdução}

$\mathrm{Na}$ sociedade ocidental, embora lide cotidianamente com a certeza da morte, a Medicina tem por paradigma lutar para promover (e em alguns casos prorrogar) a vida do paciente. Confere-se aos médicos um saber sobre-humano (GADAMER, 2006), a tal ponto que a morte, em algumas esferas da vida social, não é mais representada como parte integrante da vida, mas a constatação de um erro ou insucesso por parte dos médicos (GAUDENZI; ORTEGA, 2012). Assim, se estabelece um processo de culpa, dentro do que deveria ser visto como um processo técnico.

Discussões a respeito dessa temática na área da saúde têm sido realizadas junto a outros contextos e atores, tais como: relaçóes profissionais no Serviço de Atendimento Móvel de Urgência (SAMU) (SEMINOTTI; NEVES, 2014); atendimento às vítimas de violência (DESLANDES, 2002); médicos de CTI (MENEZES, 2000); residentes em processo de aprendizagem (BONET, 1999), mas não incluem a representação sobre a vida e a morte entre médicos que atendem em um pronto-socorro. Esses profissionais lidam diretamente com a dor e o sofrimento - próprio e alheio - face à responsabilidade por deliberar o prognóstico e tratamento.

Diante dessas lacunas, é importante ampliar o entendimento acerca dos profissionais de Medicina - aqui considerados não somente como uma categoria profissional, mas também como um grupo sociocultural - que atuam no ambiente da urgência e emergência de um hospital. Assim, o presente estudo, de orientação antropológica, busca investigar os ritos e as narrativas médicas em torno da vida e da morte num hospital de urgência e emergência, localizado em Belo Horizonte/MG.

\section{Quadro teórico}

Em seu exercício profissional, os médicos precisam lidar com três fenômenos: o corpo, a vida e a morte, cujos construtos são polissêmicos e ultrapassam a dimensão biológica do homem (MAUSS, 2003). Contudo, independentemente da especialidade ou do local de trabalho em que atuam, é preciso levar em consideração o contexto sociocultural, as características de cada indivíduo, a etapa da vida que a pessoa experimenta e seus reflexos em cada uma dessas três experiências. 
Pensar tais temáticas envolvendo a prática médica nos remete ao conceito de fato social total proposto por Mauss (2003), buscando integrar diferentes esferas constitutivas da vida social em uma compreensão transversal. Um fenômeno deve ser compreendido em sua totalidade, sem excluir nem separar os demais aspectos da realidade social, que somente pode ser apreendida na experiência vivida do indivíduo (MAUSS, 2003).

Ademais, nas ações dos indivíduos em sociedade, também se contemplam as esferas psicológica e emocional desses atos, a partir de uma classificação lógica ou de conceitos. Entende-se por conceito a noção de um grupo de seres claramente determinado, cujos limites podem ser marcados com precisão, enquanto a emoção, que contagia e brilha muito além de seu ponto de origem, não permite dizer até onde vai sua propagação (MAUSS, 2001).

Concorrem para uma concepção mais holística dos fenômenos:

- a concepção sintética de Geertz (1978), que busca integrar diferentes tipos de teorias e conceitos. Ela permite que distintos fatores - biológicos, psicológicos e socioculturais -possam ser tratados como variáveis dentro dos sistemas unitários de análise. Distingue-se da "concepção estratigráfica", que procura relaçôes sistemáticas entre fenômenos diversos, em vez de identidades substantivas entre fenômenos similares (GEERTZ, 1978);

- o pensamento complexo de Morin (2001), que se baseia em uma posição de superação do pensamento simplificador, entendido como um paradigma redutor, que isola e manipula a realidade. Ele adota o prisma da circularidade, de modo que vários aspectos, como a subjetividade e objetividade, afetam um ao outro, em um processo sucessivo de organização e desorganização (MORIN, 2001); e

- o conceito de sociedades complexas de Velho (1987), as quais se configuram pela heterogeneidade de experiências e costumes, produzindo uma extrema fragmentação e diferenciação de domínios e papéis, dando um contorno particular à vida psicológica individual. Nelas, inexiste uma separação tácita nas esferas sociais, os indivíduos interagem na interseção de diferentes mundos, podendo, a qualquer momento, transitar de um para outro, a depender de um código relevante para suas experiências (VELHO, 1987). 
Nas sociedades complexas, inclusive a ocidental, a prática médica enquanto um fato social total lida com as representações sobre a vida e a morte, que devem ser analisadas em conjunto com diversos campos disciplinares. Essa prática voltada para a vida recusa a morte como a perspectiva comum a todo ser humano (CONSORTE, 1983) e, junto da Biomedicina, incide sobre o corpo, onde se manifestam a vida e a morte. É necessário, portanto, investigar esse saber.

\section{O saber sobre o corpo nas sociedades complexas: Biomedicina e individualismo}

Mauss elege o corpo como o primeiro e mais natural instrumento do homem. O corpo continua sendo o "fato do homem", dependente, portanto, da sua dimensão simbólica (LE BRETON, 2011). Para Le Breton (2011), estudioso da corporeidade na contemporaneidade, o empreendimento anatomista que acontece entre os séculos XVI e XVII está na origem da desvalorização dos saberes populares e, em contrapartida, reforça e legitima o saber biomédico nascente, restrito a um grupo de especialistas protegido pela racionalidade - inquestionável - de seus discursos (LE BRETON, 2011).

Ademais, a consolidação da Medicina enquanto um saber científico vinculase ainda ao individualismo preponderante na cultura ocidental moderna (DUMONT, 1987), produzindo como consequências a racionalização e o afastamento do sensível, a fragmentação dos domínios e a universalização dos saberes e a interiorização e psicologização dos sujeitos.

$\mathrm{O}$ indivíduo se configura como um valor absoluto, e o corpo torna-se um agente de individualização - transformação fundamental para que a Biomedicina se cristalize como um modelo sobre o corpo e a doença (BONET, 1999). Essa nova concepção de pessoa coloca o indivíduo acima de tudo e confere um poder à Biomedicina, inaugurando uma biologia e uma medicina positivas. $\mathrm{O}$ dualismo entre o corpo - que passa a representar o que é material e objetivável - e o homem - aqui associado aos aspectos espiritual, social e psicológico - fundamenta a Biomedicina da cultura ocidental moderna, com maior grau de legitimidade enquanto saber científico (BONET, 1999).

Contudo, essa mesma construção dualista material-espiritual do modelo biomédico resulta em uma "tensão estruturante" da prática médica, na qual a delimitação do "profissional" e do "humano", ou do saber (racionalidade científica) 
e do sentir (emoções do sujeito), como dois conjuntos de representações isoladas, se manifesta de forma permanente nas práticas cotidianas dos serviços de saúde (BONET, 1999). Para se constituir como um campo de saber "científico", o saber biomédico dividiu três totalidades: o médico, o paciente e a relação entre eles. Quando aspectos dessas totalidades não se encaixavam nesse discurso criado sobre o processo de saúde-doença, essa dualidade os deslocou para o subconsciente; mas, apesar disso, todos os dias, o que foi reprimido se expressa de alguma maneira e repercute na prática biomédica cotidiana (BONET, 1999).

Daí todo o interesse desta pesquisa etnográfica, a fim de compreender a maneira como o campo médico e suas práticas científicas, incluindo a formação e o exercício profissional, definem e preveem atitudes perante o corpo, a vida e a morte.

\section{Percurso metodológico}

A presente etnografia (GEERTZ, 1978) foi realizada no contexto de um hospital de pronto-socorro de referência para a capital e para todo o Estado de Minas Gerais e também na América Latina, por sua excelência e qualificação no atendimento de demandas clínicas e traumatológicas das mais complexas e diversas. Assumese como contexto um ambiente de significado, no interior do qual elementos simbólicos se relacionam entre si, e que engloba uma parte da experiência vivida, uma parte construída e outra formada pelo ato de relacioná-las (WAGNER, 2010).

A pesquisa foi mediada por observaçōes e entrevistas semiestruturadas, guiadas por roteiro, junto aos médicos da instituição. Os entrevistados foram selecionados a partir do método conhecido como "cadeia" ou "bola de neve", em que um entrevistado sugere outro, por julgar que este tenha depoimentos importantes para a pesquisa (PATTON, 2002).

Para Geertz (1978), o produto do trabalho antropológico é interpretar as interpretaçôes, é o pensar dos pensamentos do próprio objeto de estudo à procura de uma compreensão dos significados que tais grupos partilham; em outras palavras, os aspectos culturais desse grupo. A procura desse significado, por meio dessa ciência interpretativa, explica o conceito de cultura semiótico, weberiano, que compreende o homem como um animal amarrado a teias de significados que ele mesmo teceu, sendo a cultura essas teias e a sua análise (GEERTZ, 1978). Essa perspectiva êmica de investigação (POSEY, 1986), em que se dá "voz" ao 
interlocutor de pesquisa - os profissionais de Medicina -, permite identificar e compreender as dificuldades enfrentadas e suas implicações no cuidado a pacientes.

Os dados foram abordados a partir da técnica de análise de conteúdo (BARDIN, 2006). Tal método contempla um conjunto de procedimentos sistemáticos com a finalidade de se analisar os discursos proferidos pelo objeto de estudo. Segundo Bardin (2006), a técnica possui 3 etapas, a saber: pré-análise (organização dos dados); exploração do material (definição de categorias de análise); e tratamento dos resultados, inferência e interpretação (análise reflexiva).

\section{Considerações éticas}

Esse estudo é parte de um projeto maior, intitulado "VIDAS EM RISCO: uma abordagem antropológica sobre as representações da morte entre médicos que trabalham em setores de urgência”, aprovado pelo Comitê de Ética da Universidade Federal de Minas Gerais (CAAE: 03751612.0.0000.5149), juntamente com o Comitê de Ética em Pesquisa da Fundação Hospitalar de Minas Gerais (CEP/ ADC/FHEMIG: 022/2012 - SIPRO: 29128/2012-7). A pesquisa está em acordo com a Resolução no 466, de 12 de dezembro de 2012 do Conselho Nacional de Saúde. Para assegurar o anonimato dos entrevistados, eles foram identificados, respectivamente, pela ordem da entrevista, pela especialidade médica e pelo sexo (F para feminino, $\mathrm{M}$ para masculino).

\section{Abordagens e interpretações}

Nesta etnografia, ao longo de nove meses de trabalho de campo, foram entrevistados 43 médicos plantonistas (25 homens e 18 mulheres), com idades entre 28 e 69 anos, que trabalham em setores específicos para pacientes graves com risco de morte. Da análise de conteúdo, emergiram as categorias: "Uma relação de mão-dupla: articulações entre o habitus e o campo na atuação médica" e "O médico mágico’: a potência do discurso médico”.

\section{Uma relação de mão-dupla: articulações entre o habitus e o campo na atuação médica}

Nesta categoria, os profissionais trazem a forma como o médico baliza a sua relação - com os diversos sujeitos e situações - na prática profissional. Esta anestesista define o que é ser médica: 
Ser médica é uma praga que fica impregnada por debaixo da pele. É quase que instin-

tivo, a pessoa queixando-se de dor ao seu lado, você fica incomodada, principalmente se é um ente querido seu, você já quer tirar a dor daquela pessoa; é instintivo, eu sou treinada para tirar a dor, então está com dor ao meu lado e reclamou, eu quero tirar. A pessoa diz: 'Ah, estou com dor de cabeça, mas não quero tomar nada não'. Aí eu digo: 'Como assim?! Você quer ficar sentindo dor?'. Igual uma pessoa que tem uma doença e não quer tratar: 'Como assim?! Não quer tratar? Você tem três crises de dor de cabeça por semana e não quer se tratar?'. E isso é o tempo todo, imagino que deva ser insuportável para as outras pessoas eu me portar assim (E7, Anestesista, F).

Para Gadamer (2006), o médico precisa "ver além do que é o objeto próprio de seu saber e de seu ser-capaz-de-fazer, se ele quiser ser o verdadeiro médico" (GADAMER, 2006, p. 51). Em sua prática, o médico bascula entre uma presença profissional afastada do humano e um compromisso humano, mas a arte médica inclui saber se retirar e liberar o outro para que retome a sua vida, o que torna essa práxis sempre uma escolha entre possibilidades, carregando em si uma relação com o "ser" do homem (GADAMER, 2006).

Questionados sobre se haveria ou não uma imbricação da esfera profissional na esfera pessoal e vice-versa, especialmente em casos de risco de morte, os médicos entrevistados confirmam ser muito difícil desvincular-se da atuação profissional:

Você larga o plantão, mas você, ao mesmo tempo, você não larga o plantão. Às vezes acontece de eu ligar, mandar mensagem, ver como é que ficou, porque no plantão o cuidado deveria ser uma coisa contínua. Mas não é porque eu saí daqui que a coisa acabou, não é uma chave que você chega e desliga, é um processo, então, quando você sai do plantão, até você acostumar com a ideia de que saiu do plantão exige toda uma elaboração. [...] Eu até sonho muito que eu estou trabalhando, vira e mexe eu estou aqui à noite através do sonho (E40, Clínica Médica, M).

O comportamento da pessoa atuando como médico parece estar completamente condicionado à lógica da localização institucional, como neste excerto:

Tudo que acontece aqui eu levo para casa e vai para a cama com a gente. (...) Desligar, quando você sai daqui, não desliga não. Você continua ligado, você continua sabendo, se o paciente ficou grave e você foi embora, você quer saber como ele está. Esses casos a gente vai acompanhando e quando morre... a gente acaba falando em casa, por exemplo, eu falo muito com o meu marido, com meu filho, às vezes é uma forma de você desabafar (E23, Clínica Médica, F).

Assim, ao longo de todo o processo etnográfico, observa-se nas atitudes e depoimentos dos profissionais médicos uma extensão do que é vivido, tanto em sua esfera subjetiva quanto em sua prática. Consoante a esses aspectos se inserem 
as noções do ethos (ALVES, 2007), do campo social e do habitus (BOURDIEU, 2003, 2004) desses profissionais.

Etimologicamente, êthica significa a interioridade do ato humano, situada na origem de uma ação genuinamente humana e que emerge do sujeito moral (o âmago do agir, o sentido da intenção), mas também significa éthos, indicando a questão dos hábitos, costumes, usos e regras, o que se materializa na assimilação social dos valores (ALVES, 2007). Bourdieu (2004) sugere uma "filosofia da ação" baseada na "relação de mão-dupla" entre as estruturas objetivas pertencentes aos campos sociais - e as estruturas incorporadas - pertencentes ao habitus. O campo social é definido a partir das relações de forças entre dominados e dominantes, caracterizadas por suas próprias regras e hierarquias, na medida em que os indivíduos nele inseridos reconhecem e agem conforme o que é determinado por ele, enquanto o habitus orienta a prática dos indivíduos e os acompanha, produzindo efeitos em outras experiências pessoais, constituindo-se por princípios geradores de percepções e comportamentos produtores de valores culturais e referências identitárias (BOURDIEU, 2004). É uma estrutura do mundo social que, ao mesmo tempo, é estruturada pelo sujeito, que aprende com o próprio corpo em sua vivência no mundo.

No entanto, nas sociedades complexas, a coexistência de distintos mundos constitui a sua própria dinâmica (VELHO, 1987). Logo, o habitus do médico, sua disposição e seus dispositivos, não são necessariamente seus, eles derivam de uma posição geral da sociedade ou da cultura. Entende-se cultura como um processo pelo qual os homens orientam e dão significado às suas ações, a partir de uma manipulação simbólica - atributo fundamental de toda a prática humana (GEERTZ, 1978). Na cultura ocidental, os médicos são treinados para lidar com a doença, mas esta médica admite emoções contraditórias:

[...] Por isso que eu te disse que eu tenho uma sobrecarga emocional e stress algumas vezes, mas, por outro lado, me aproxima muito das famílias, eles sentem que eu estou junto, porque muitas vezes eu encho os olhos d'água, choro junto, então eu não consigo fazer essa separação (E28, Clínica Médica, F).

O médico, em seu exercício profissional, não se restringe apenas à sua racionalidade científica ao ministrar um tratamento e lidar com o enfermo, mas também com seus significados subjetivos e sua trajetória pessoal (LAPLANTINE, 1991). Perante as contingências do tratamento e da própria fatalidade da morte, as 
ações dos médicos envolvem sua legitimidade profissional, definida pelo campo

médico, e suas próprias emoções - atitudes que envolvem a intersubjetividade nas relações cotidianas dos sujeitos sociais (KOURY, 2004). Tais experiências emocionais, entendidas como singulares, experienciadas por um ator social específico, também resultam da relação entre os indivíduos, a cultura e a sociedade (KOURY, 2004).

No campo de fala dos entrevistados, uma nítida intersubjetividade se revela, principalmente, quando reportam a lembrança do primeiro óbito a que assistiram ou de casos marcantes de morte ocorridos ao longo da trajetória profissional, como neste relato:

Lembro-me de um momento da minha trajetória profissional que não consigo esquecer. Estava de plantão aqui no hospital e minha mulher me ligou pedindo para que eu pegasse um resultado de teste de gravidez logo aqui perto. Eu ainda não tinha sido pai. Chegando ao hospital abri o envelope e deu positivo, fiquei muito feliz na hora. Em seguida fui ver uma criança que havia dado entrada no hospital vítima de um acidente de bicicleta; fui ver como ela estava e fiquei sabendo que ela havia falecido há poucos minutos. Fiquei desconcertado e não sabia como falar para a família. E o mais engraçado de tudo é que eu já havia dado muitas notícias de óbito, mas nessa eu travei e até hoje a lembrança desta me afeta. Tudo parecia uma ironia do destino: eu acabava de saber que seria pai e, ao mesmo tempo, teria que dar a notícia a um pai que o seu filho havia falecido. Isso bateu de frente com a minha própria vida e me abalou muito. [...] Uma coisa difícil, simplesmente porque eu estava com um papelzinho no bolso que dizia que eu seria pai. (E14, Cirurgia Geral, M).

Embora o médico tenha todo um aparato de técnicas científicas e aprendizagens para lidar com o corpo, a vida e a morte no contexto de um hospital, é a sua experiência pessoal e o seu exercício profissional cotidiano que definem e processam a sua forma de lidar com o conhecimento.

Como visto nos depoimentos, a prática médica não se restringe ao trato de uma moléstia física, afinal, os médicos também têm um corpo que sente a dor e também reage a ela. Eles são seres no mundo, afetados pelas situações que vivenciam na prática profissional. Isso contesta certa indiferença do médico em relação ao outro, sustentada tanto pelo ensino médico quanto pelo senso comum. Uma suposta atitude blasé possibilitaria uma maior objetividade e racionalidade, enquanto preservaria a vida subjetiva e pessoal: é o estar "próximo fisicamente e distante mentalmente". O termo blasé foi utilizado por Simmel (1987) para se referir ao homem metropolitano que, por estar exposto a muitos estímulos, não consegue reagir a todos com a energia apropriada. Para além disso, sensibilidades, 
juízos de valor e envolvimento também se relacionam na atuação profissional, como pode ser visto neste excerto:

Eu olhava para os "bandidos" que apareciam aqui e falava assim: "eu nunca vou trabalhar nesse hospital, porque eu não sirvo para cuidar de gente ruim não, gente que não presta, esse povo merece mesmo é se f..., e que morra”. Mas na hora que ele chega aqui, é um corpo de uma pessoa que ainda está viva precisando daquela mãozinha do médico ali para poder tratar e resolver o problema. Independente se for bandido ou mocinho, eu vou fazer o que eu tenho que fazer para tratá-lo, ainda que eu descubra que essa pessoa não merecesse isso. [...] Mas eu trato com muito mais carinho e empenho aquele que é o mocinho da história, aquela pessoa de bem; o bandido eu não maltrato, mas também não fico naquela coisa de carinho e tal (E21, Clínica Médica, M).

$\mathrm{Na}$ fala acima, percebe-se que o corpo oculta/revela "mocinhos e bandidos" de uma sociedade violenta, e a técnica a favor do restabelecimento da vida é utilizada de forma indiscriminada e independente de "quem" seja o paciente. $\mathrm{O}$ vínculo e a relação com o paciente, entretanto, tornam-se diferenciados a partir do momento em que o profissional médico descobre a identidade/procedência desse corpo. Assim, técnica e relação são duas ações apostas num atendimento de urgência e emergência, em que, muitas vezes, juízos de valor e ética médica são desafiados em conflitos que contrapõem a formação e o exercício profissional, o sujeito real e o ideal que ele mesmo ou outros têm dele. A Medicina é uma prática profissional que envolve decisões complexas, ao médico são conferidas responsabilidades sobre escolhas alicerçadas em perspectivas técnicas, sociais e morais (MENEZES, 2000).

Assim, uma linha tênue permeia as fronteiras das relações intersubjetivas que permitem compreender as ações e as percepções de um sujeito em uma determinada realidade social. Em seu exercício profissional, o médico articula suas ações nesses liames que envolvem o lado ético, profissional e subjetivo (GADAMER, 2006). Tampouco se pretende criar antagonismos de categorias como objetivo/subjetivo, mas desvendar como essas esferas conceitualmente opostas se inter-relacionam nas convivências cotidianas dos sujeitos sociais, como apontado na próxima categoria analítica.

\section{"O médico mágico": a potência do discurso médico}

Aqui, os profissionais de um dos maiores hospitais no atendimento ao politrauma e a queimados da América Latina lidam com pacientes e famílias que temem a perda da vida, e por esse motivo depositam no médico certa devoção para a cura 
da doença. No cotidiano dos plantões, os médicos se mostram capazes de sofrer

de modo solidário com os pacientes e familiares, e de exercitar a compaixão colocar-se no lugar do outro -, como afirma este clínico:

Principalmente quando você se coloca no lugar do paciente ou da família, e eu acho que essa não separação é até boa porque a gente continua a 'ser humano', se não a gente começa maquinizar demais as coisas: 'Ah, eu sou médico, não posso misturar as coisas', fica uma relação muito seca, sem empatia, sem esse sentimento mesmo de estar no lugar do outro, ver que o paciente está sofrendo, está sentindo dor, a família está sofrendo. Então se a gente separar, a gente perde essa humanização da Medicina (E26, Clínica Médica, M).

Ao lutar contra a tecnicização excessiva que torna a prática médica menos humanizada, os entrevistados contrariam a esperada "neutralidade afetiva" proposta por Parsons (1951), que classifica o médico como universalista, funcionalmente específico e afetivamente neutro. $\mathrm{O}$ caráter universalista implica que o médico não deve dar vazão a relações sentimentais com o enfermo, enquanto o controle social existente na comunidade médica, mediado por um papel objetivo e neutro, permitiria regular o contato físico e emocional entre médico e paciente (PARSONS, 1951).

Referindo-se à percepção de familiares e do paciente quanto à atuação do médico diante da morte, dois profissionais explicam:

Eles encaram a gente como o salvador, eles olham para a gente e dizem: "É Deus no céu e você aqui, para me iluminar, eu espero que ilumine e me salve". Você já viu aquela situação: "Chame o médico! Chame o médico!" O que adianta chamar o médico se você não tem um instrumento, nada ali que possa ajudar a salvar a vida? $\mathrm{O}$ médico sem o medicamento, de repente não vai adiantar nada. Chama o médico, beleza, ele faz o diagnóstico, mas se não há instrumentos, o tratamento não dá para fazer. A pessoa acha que o médico é a pessoa capacitada para salvar por um "toque de mágica” e resolver o problema (E21, Clínica Médica, M).

Eu acho que o paciente quer que você salve a vida dele, mesmo que você tenha que vender a sua alma para o diabo. Têm vários perfis, eu tenho paciente que vira e fala: "Faz o que você quiser, mas resolve!" [...] Tem paciente que você fala para ele que ele tem uma doença incurável, ele vai embora e nunca mais te olha na cara. A maioria dos pacientes espera que o médico faça alguma coisa por ele, então se ele está com colesterol alto, ele espera que você abaixe o colesterol dele olhando para ele, e não que ele pare de comer, que faça atividade física; existe uma imaturidade do doente em relação às doenças e ao morrer. E o médico também muitas vezes não gosta de falar sobre e foge nessa hora; há pacientes em cuidados paliativos, ou seja, com uma enfermidade sem prognóstico que não sabiam do seu quadro, porque o médico simplesmente não falou. Eu acho que eles pensam que o paciente tem a fantasia de que o médico é capaz de driblar a morte, e quando chega nesse assunto chega de um jeito muito ruim (E33, Clínica Médica, F). 
Nenhuma outra profissão no mundo ocidental adquiriu tanto poder em definir realidades como a Medicina (MACHADO, 1997). Nesse aspecto, Laplantine (1991) a define como uma moral, uma vez que ela, por meio de seu saber, evoca o que é bom e direciona as condutas. A atividade médica, dotada de princípios ético-morais, estabelece uma relação muito peculiar com o consumidor (paciente) de seus serviços, que requer a um só tempo confiança, sigilo e credibilidade (FOUCAULT, 2003).

Ainda assim, o profissional reconhece seus limites diante da autonomia e do desejo do paciente, sua impotência e sua dificuldade em admitir a possibilidade da morte. Conjugado a esse pensamento, Bourdieu (1996) confere ao discurso um impulso performático, em que o poder das palavras não está nelas mesmas, mas no ato de delegação que institui o porta-voz que as pronuncia. É como se, no presente caso, o médico, enquanto porta-voz autorizado, conseguisse agir com palavras em relação a outros agentes, na medida em que a sua fala concentra todo o capital simbólico acumulado pelo grupo que lhe conferiu o mandato e do qual ele - o médico - é, por assim dizer, o procurador (BOURDIEU, 1996). Para Bourdieu (1996), o poder logrado por certas palavras de ordem em obter trabalho sem dispêndio de energia, por meio de sua "ação mágica", estaria fundamentado no capital acumulado pelo grupo mediante sua experiência profissional.

É preciso, então, "estabelecer a relação entre as propriedades do discurso, as propriedades daqueles que o pronunciam e as propriedades da instituição que o autoriza para pronunciá-las" (BOURDIEU, 1996, p. 89). O discurso médico é fundamentado por meio do capital simbólico acumulado pela categoria profissional a que pertence. Aos médicos que atuam no serviço, cabe uma forma de resposta a essas expectativas: fazer o possível - e o impossível - para restabelecer a vida desses pacientes. Tal conduta reforça o éthos da profissão (ALVES, 2007).

Dois pediatras explicam:

As pessoas, de um modo geral, acham que a gente não sente a morte do outro, eles acreditam que você está tão acostumado a ver gente morrer, que mais um ou menos um não vai fazer diferença nenhuma, e isso é chocante para mim, porque isso não é verdade, nós sentimos cada um que morre (E39, Pediatra, F).

Aqui você precisa ter um jogo de expressões, você não pode deixar transparecer certas coisas para os familiares e para o doente. Se, por exemplo, o paciente está muito mal, a gente não pode expressar agonia, desespero, indiferença, tudo isso a família percebe, e o paciente, quando consciente, também (E36, Pediatra, M). 
Sob outra perspectiva, a esperada frieza do profissional diante das situações

vividas no pronto atendimento estaria relacionada ao distanciamento proposto pelo modelo biomédico e utilizado na prática profissional. Porém, a percepção dos médicos em relação à forma como pacientes e familiares veem seu posicionamento diante da morte - envolto por indiferença em relação à morte dos seus pacientes se contrapõe à maneira como os próprios médicos se veem ou agem. Além disso, a imagem social, especialmente do paciente que atribui ao médico o poder de evitar a morte, com expressões como "Doutor, minha vida está em suas mãos", aumenta neles a pressão e a frustração diante da impossibilidade de cura e a certeza da morte. Uma anestesista revela:

Muitas vezes, principalmente quando há algum óbito, a gente dá a notícia para o familiar, em seguida vai para o banheiro, chora, e depois volta fazendo "cara de paisagem" (E7, Anestesista, F).

Quando se depara com situações que envolvem, principalmente, a impossibilidade de cura e a morte, o médico precisa "administrar" seu afeto em relação ao sofrimento do outro. Essa dosagem implica utilizar algum "escudo ou máscara" para se proteger diante de pacientes, familiares e demais profissionais envolvidos. Embora não anule sua sensibilidade em relação aos problemas alheios, diante de vários fatos melindrosos inerentes à profissão, essa "máscara", de certo modo, obriga seu "eu" a resistir perante os acontecimentos. A prática médica defronta o lado afetivo e o saber aprendido na Academia: é a tensão estruturante da prática médica definida por Bonet (1999).

Ademais, na luta para evitar e afastar a morte, o ensino e a prática médica se ancoram no sentido de propor novas pesquisas e formas de prolongar a vida, as quais, quando conseguem postergar a morte, lhes conferem certa autoridade. Porém, quando a morte acontece, ela coloca em risco a sua credibilidade profissional, pois sua assinatura no atestado de óbito confirma sua impotência contra a morte. Revela-se outra contradição do poder médico: embora o compromisso do médico seja com a vida, a morte sempre estará presente na atuação do profissional (CONSORTE, 1983). Assim, o processo de medicalização da morte incumbe ao médico um papel fundamental, especialmente no que se refere à sua responsabilidade técnica e ética diante dela.

Stedeford (1992) sustenta que atitudes como reserva diante do moribundo, e até um aparente descaso, demonstram, acima de tudo, um mecanismo defensivo 
de que o médico lança mão, na tentativa de se proteger face ao perigo de um envolvimento mais forte com o doente. Ou ainda, isolamento para disfarçar a sensação de impotência diante do que mais combateu: a impossibilidade de cura e a morte. Tais "fugas evasivas" servem para balizar sua sensibilidade. Interligado a essa ideia, Taylor (1997) destaca que as ações humanas são orientadas por um pensamento moral, relacionado intrinsecamente à noção de "bem" - usado no sentido mais geral, como sendo algo digno e admirável - e do self ou pessoa. Tais noções estão vinculadas, no sentido de que todo ser humano (que, por extensão, é uma "pessoa”) é sensível aos problemas dos outros. A sensibilidade, nesse aspecto, vem "de fora", provocada também pela sociedade.

Durante o período de campo, houve o suicídio de uma médica do hospital, que trabalhava na emergência. Um médico utilizou esse exemplo para ressaltar a importância do apoio psicológico:

Eu acho que esse preparo psicológico tinha que ser feito. Tem muito médico surtando por aí; aqui no hospital mesmo temos vários exemplos de crises de stress, agressão. Recentemente, uma residente suicidou, enforcando-se; a garota era linda, com vida social normal, com uma carreira invejada, formou-se em Medicina, estava concluindo a residência; a gente conversava com ela aqui e via que aparentemente era uma pessoa normal e muito boa de serviço. Mas você concorda comigo que algo certamente não estava indo bem com ela, e essa ajuda psicológica talvez seria uma medida preventiva para esses casos, quem sabe se ela tivesse sido acompanhada isso não teria sido evitado? (E11, Cirurgião Geral, M).

Quando a sensibilidade não é canalizada para outras esferas, observa-se um comprometimento da saúde do médico, principalmente no que tange a transtornos mentais, uso de drogas e autoextermínio, conforme apontado nesse depoimento.

Kaufman (1991) destaca que o paciente é tido como alguém que precisa de uma ajuda externa, é aquele objeto de uma ação, que é executada pelo médico, agente dotado de uma força, o que configura uma relação de poder e submissão. Subjacente à doença, o paciente leva seus problemas psicossociais decorrentes da enfermidade. Nesse momento, o médico executa o papel de afastar o sofrimento, devendo ser um "verdadeiro mágico", que atende a um desconhecido, com sintomas orgânicos diversos, muitas vezes interligados a problemas emocionais e sociais. O "médico mágico" acaba por receitar um remédio para curar um sintoma que, na verdade, faz parte de um problema mais amplo, enquanto revela a fragilidade humana. 
Pacientes que dão entrada em prontos-socorros temem perder a vida; por esse motivo, depositam no médico certa devoção para a cura da doença/trauma. Um médico destacou o comportamento cooperativo desses pacientes:

Ele deixa examinar; às vezes ele estava começando a cochilar, chegou alguém ele acorda, porque ele sabe que precisa daquela ajuda para sair vivo lá de dentro. Então os pacientes que estão aqui dentro, eles, de certa forma, são muito acessíveis, porque estão 'morrendo de medo de morrer', porque é uma situação inesperada para eles e eles confiam plenamente no médico que está ali dentro (E11, Cirurgia Geral, M).

Nesse aspecto, segundo Balint (1998), a idealização do médico pode ser compreendida como uma função "apostólica do médico", ou seja, os pacientes acabam se submetendo às normas que os médicos prescrevem, o que na linguagem do autor seriam "fé e mandamentos" inquestionáveis.

Porém, um cirurgião admite seu sofrimento:

O médico sofre quando ele se sente um agente catalisador da morte, porque existem situações no nosso dia a dia que são situações chamadas iatrogênicas. Tudo o que aconteceu com o paciente que partiu do médico é iatrogênico, então existem as iatrogenias evitáveis e as inevitáveis. Quando uma iatrogenia pode catalisar uma evolução desfavorável, o médico sofre muito, e nós não temos como evitar isso não, muitas vezes nós sentimos. (E8, Cirurgia Geral, M).

Na prática médica, tem-se o desejo da imortalidade e da superação da morte: idealiza-se um ser onipotente, capaz de anular a finitude do homem (SIMON, 1971). Este ser idealizado é chamado pelo autor de "ser tanatolítico" - do grego tanatos, e lisis, destruição. Em qualquer cultura, existe esse ser tanatolítico personificado, normalmente, na figura do sacerdote ou do médico, cuja "idealização" ocorre principalmente com a descoberta da cura de moléstias consideradas incuráveis.

Tal idealização é cabível no incentivo a novas pesquisas científicas. Todavia, se levada ao extremo, torna-se nociva: quando existe uma identificação desmedida do médico com o seu "ser tanatolítico", ele se vê um ser onipotente, que experimenta sentimentos de fracasso decorrentes da não superação da cura e da morte em sua práxis. Segundo Balint (1998), no médico são geradas culpa e pressão oriundas internamente - decorrentes de seu próprio narcisismo - e externamente - pois a cultura nutre o ideal de um médico que garanta a imortalidade das pessoas.

Portanto, médicos e familiares desejam o paciente vivo, mesmo que ambas as partes reconheçam ou temam as sequelas previsíveis, como explica esta plantonista: 
Até o paciente ir a óbito, é uma luta, tanto uma luta para deixar o paciente vivo, como também uma luta interna: 'Eu não posso deixar esse paciente morrer'. A gente não consegue ter um desapego como deveria. Eu acho que isso é reforçado pela sociedade ocidental, onde as pessoas não aceitam a morte. O próprio parente do paciente não quer que ele morra e acaba transferindo isso para o médico. Com isso a gente luta para manter o paciente vivo e lutamos contra a morte (E3, Anestesista, F).

Muitos médicos ressaltaram a determinação dos familiares de lograr a manutenção da vida a todo custo, independentemente do sofrimento do paciente ou das suas perspectivas de sobrevivência, o que se reflete diretamente no cuidado médico - situação evidenciada, principalmente em relação aos pacientes com sequelas crônicas, que permanecem internados em um setor específico da instituição.

Compreende-se, portanto, que a cobrança imposta aos médicos no meio acadêmico, na sociedade e, enfim, em todos os campos, exige do médico "arrancar" um paciente da morte, levando-o a direcionar todos os esforços para fazê-lo. $\mathrm{O}$ êxito nesse propósito não garante a realização do profissional; pelo contrário, muitos relataram suas dificuldades no cuidado a pacientes com sequelas graves e definitivas, fazendo-os refletir que evitar a morte de forma obstinada pode não ser a principal finalidade da atuação médica. . Outra questão ecoa sem resposta: o discurso biomédico - e, por extensão, sociocultural - a favor da cura, encontraria sua negação quando precisa lidar com os efeitos dessa atuação?

\section{Considerações finais}

A prática médica na sociedade ocidental institui questionamentos permanentes. Escutar os profissionais médicos permite identificar e compreender muitas das dificuldades enfrentadas por eles e suas implicações no cuidado a pacientes. Ao abordar a atuação daqueles que lidam com os limites da vida e da morte cotidianamente, deparamo-nos com uma riqueza de sentidos e complexidades.

Neste estudo sobre a prática médica, observa-se uma mobilização em prol da vida, em que a ética profissional, o modelo biomédico e as técnicas científicas dominam a dinâmica de uma instituição. Entretanto, sensibilidades e afetividades também medeiam a atuação desse profissional, ainda que de forma velada pela estrutura biomédica.

Embora o médico pertença a um campo profissional específico, que deve, por um lado, garantir a vida e, por outro, reagir, de forma profissional e ética à morte, nota-se uma espécie de contaminação circular entre sua condição de 
profissional e sujeito. Essa imbricação institui uma circularidade singular, na qual

o ético e o cultural, a preparação profissional e a imagem social se influenciam mutuamente, comprovando o caráter complexo e dinâmico da atuação médica diante dos fenômenos de vida e de morte. ${ }^{1}$

\section{Referências}

ALVES, J. A. Éthos/êthos, o ser e o dever - O desenvolvimento de um conflito. J Ciências Cognitivas [online]. 2007. Disponível em: <http://jcienciascognitivas.home.sapo.pt/0704_alves.html>. Acesso em: 13 abr. 2015

BALINT, M. O médico, o seu doente e a doença. Lisboa: Climepsi, 1998.

BARDIN, L. Análise de conteúdo. Lisboa: Ediçōes 70, 2006.

BONET, O. Saber e sentir: uma etnografia da aprendizagem da Biomedicina. Physis: Revista de Saúde Coletiva. Rio de Janeiro, v. 9, p. 123-150, 1999.

BOURDIEU, P. A economia das trocas linguisticas. O que falar quer dizer. São Paulo: Edusp, 1996.

. O poder simbólico. Rio de Janeiro: Bertrand Brasil, 2003.

. A economia das trocas simbólicas. São Paulo: Perspectiva, 2004.

CONSORTE, J. A morte na prática médica. In: MARTINS, J. S. (Org.). A morte e os mortos na sociedade brasileira. São Paulo: Hucitec, 1983.

DESLANDES, S. F. Frágeis deuses: profissionais da emergência entre os danos da violência e a recriação da vida. Rio de Janeiro: Fiocruz, 2002.

DUMONT, L. Ensayos sobre el individualismo. Madri: Alianza, 1987.

FOUCAULT, M. O nascimento da clínica. Rio de Janeiro: Forense Universitária, 2003.

GADAMER, H-G. O caráter oculto da saúde. Petrópolis: Vozes, 2006.

GAUDENZI, P.; ORTEGA, F. O estatuto da medicalização e as interpretações de Ivan Illich e Michel Foucault como ferramentas conceituais para o estudo da desmedicalização. Interface (Botucatu), v. 16, n. 40, p. 21-34, 2012.

GEERTZ, C. A Interpretação das Culturas. Rio de Janeiro: Zahar, 1978.

KAUFMAN, A. Teatro pedagógico: bastidores da iniciação médica. São Paulo: Agora, 1991.

KOURY, M. G. Introdução a Sociologia da Emoção. João Pessoa: Manufatura, 2004.

LAPLANTINE, F. Antropologia da doença. São Paulo: Martins Fontes, 1991.

LE BRETON, D. Antropologia do corpo e modernidade. Petrópolis: Vozes, 2011.

MACHADO, M.H (Org.). Os médicos no Brasil: um retrato da realidade. Rio de Janeiro: Fundação Oswaldo Cruz, 1997. 
MAUSS, M. Algumas formas primitivas de classificação. In: . Ensaios de sociologia. São Paulo: Perspectiva, 2001. p. 399-455. _. Sociologia e antropologia. São Paulo: Cosac, 2003.

MENEZES, R. A. Difíceis Decisōes: uma abordagem antropológica da Prática Médica em CTI. Physis: Revista de Saúde Coletiva. Rio de Janeiro, v. 10, n. 2, jul./dez., 2000.

MORIN, E. O método II: a vida da vida. Porto Alegre: Sulina, 2001.

PARSONS, T. The social system. New York: Free Press, 1951.

PATTON, M. Q. Qualitative research e evaluation methods. Londres: Sage, 2002.

POSEY, D. A. Introdução: Etnobiologia, teoria e prática. Suma Etnológica Brasileira. D. Ribeiro. Petrópolis: Vozes/FINEP, v. 1, p. 15-25, 1986.

SEMINOTTI, E.; NEVES, E. Dos Dramas de Narciso: reflexões antropológicas a partir de uma etnografia de um Serviço de Atendimento Móvel de Urgência (SAMU) de João Pessoa - PB. Ilha: Revista de Antropologia, v. 16, n. 1, p. 175-202, dez. 2014.

SIMMEL, G. A metrópole e a vida mental. In: . Ofenômeno urbano. Rio de Janeiro: Guanabara, 1987.

SIMON, R. "O complexo tanatolítico" justificando medidas da psicologia preventiva para estudantes de medicina. Bol. Psiq. v. 4, n. 4, p. 113-115, 1971.

STEDEFORD, A. Encarando a morte: uma abordagem ao relacionamento com o paciente terminal. Porto Alegre: Artes Médicas, 1992.

TAYLOR, C. As fontes do self: a construção da identidade moderna. São Paulo: Loyola, 1997. VELHO, G. Individualismo e cultura: notas para uma antropologia da sociedade contemporânea. Rio de Janeiro: Jorge Zahar, 1987.

WAGNER, R. A Invenção da Cultura. São Paulo: Cosac Naify, 2010.

\section{Nota}

J. de S. Aredes participou da concepção do projeto; coleta, análise e interpretação dos dados; e redação do artigo. A. L. Modesto participou da concepção do projeto; análise e interpretação dos dados; e redação do artigo. 


\section{Abstract}

"Between lives and deaths, between masks and escapes": a study on hospital medical practice The complex societies attribute to the physicians a superhuman knowledge that defies death and refuse to recognize death as part of life. In urgency and emergency services, several professionals work daily and nightly close to life and death. This article analyzes the Western medical practice, based on an ethnographic study conducted with medical professionals who work in a big city emergency and urgency health service. We aimed to understand how these doctors, as individuals, subjects and professionals, deal with life and death in professional praxis. Data analysis pointed to ethical, institutional, cultural and idiosyncratic relations in medical action facing the life(ves) and death(s) of the assisted people.

Key words: Biomedicine; discourse; medical practice. 